\title{
Performance of the Chemical and Electrochemical Composites of PPy/CNT as Electrodes in Type I Supercapacitors
}

\author{
S. C. Canobre, F. F. S. Xavier, W. S. Fagundes, A. C. de Freitas, and F. A. Amaral \\ Laboratório de Armazenamento de Energia e Tratamento de Efluentes (LAETE), Instituto de Química, \\ Universidade Federal de Uberlândia (UFU), Avenida João Naves de Ávila 2121, 38408-100 Uberlândia, MG, Brazil \\ Correspondence should be addressed to S. C. Canobre; scanobre@iqufu.ufu.br
}

Received 25 October 2014; Revised 27 December 2014; Accepted 30 December 2014

Academic Editor: Yuhua Xue

Copyright (C) 2015 S. C. Canobre et al. This is an open access article distributed under the Creative Commons Attribution License, which permits unrestricted use, distribution, and reproduction in any medium, provided the original work is properly cited.

Polypyrrole ( $\mathrm{PPy})$ is one of the most studied conducting polymers and a very promising material for various applications such as lithium-ion secondary batteries, light-emitting devices, capacitors, and supercapacitors, owing to its many advantages, including good processability, easy handling, and high electronic conductivity. In this work, PPy films were chemically and electrochemically synthesized, both in and around carbon nanotubes (CNTs). The cyclic voltammograms of the device, composed of the electrochemically synthesized PPy/CNT composites as working and counter electrodes (Type I supercapacitor with p-type doping), showed a predominantly capacitive profile with low impedance values and good electrochemical stability, with the anodic charge remaining almost constant $(11.38 \mathrm{mC})$, a specific capacitance value of $530 \mathrm{~F} \mathrm{~g}^{-1}$ after 50 charge and discharge cycles, and a coulombic efficiency of $99.2 \%$. The electrochemically synthesized PPy/CNT composite exhibited better electrochemical properties compared to those obtained for the chemically synthesized composite. Thus, the electrochemically synthesized PPy/CNT composite is a promising material to be used as electrodes in Type I supercapacitors.

\section{Introduction}

Polymers are macromolecules formed of small structural units (the monomers). The conducting polymeric materials have gained attention in the last 50 years, owing to easy processing and low costs when compared to metals like iron, aluminum, copper, and others. Recently, new polymer classes have been studied, owing to their excellent conducting properties. They are known as "conducting polymers" and have molecular bonds composed of conjugated double $(\mathrm{C}=\mathrm{C}-$ $\mathrm{C})$, which result in an electronic delocalization along the polymeric chain [1]. The most important characteristic of the electrically conducting polymers is not just the intrinsic conductivity, but the ability to reversibly change their oxidation and reduction states, resulting in a wide range of electronic conductivity values that vary from low (fully reduced state) to high (partially oxidized state) [2].

Among the conducting polymers, polypyrrole (PPy) has attracted much attention in terms of its wide range of applications, which are based on the reversibility between the redox states [3], showing good conducting properties, and the fact that it is easily chemically or electrochemically synthesized [4-7]. However, PPy presents some structural defects during its synthesis, such as impurities that may be incorporated into the polymeric chains or the presence of ramifications, which are the result of nucleophilic attack in positions other than the 2 and 5 positions. Therefore, every time the polymer preferentially grows in the ortho position, it results in branched chains. These structural defects of the PPy can be minimized by template synthesis. In a template synthesis, the host matrix determines the size, spatial orientation, and shape of the synthesized polymer [2]. Carbon nanotubes (CNTs) were discovered in the 1990s and were classified as single-walled carbon nanotubes (SWCNTs) and multiwalled nanotubes (MWCNTs) [8]. SWCNTs are formed from a rolled graphite leaf with closed extremes, whereas MWCNTs are made up of concentric SWCNTs [9]. These materials exhibit excellent morphological, electrical, optical, thermal, chemical, and mechanical properties [10]. $\mathrm{CNT} / \mathrm{PPy}$ composites have intensified properties, owing to the synergistic effect between the constituent materials. Conducting polymers increase the electronic conductivity of 
the composites and the CNTs mechanically and thermally reinforce these materials [11].

Wang et al. (2007) studied PPy/SWCNT composites for applications as electrodes in symmetric supercapacitors. Specific discharge capacity values were obtained using cyclic voltammetry $(\mathrm{CV})$ in $1 \mathrm{~mol} \mathrm{~L}^{-1} \mathrm{KCl}$ solution at $10 \mathrm{mV} \mathrm{s}^{-1}$. The values were 223 and $202 \mathrm{Fg}^{-1}$ for functionalized and nonfunctionalized SWCNTs, respectively. During functionalization, carboxylic groups can be incorporated into the nanotubes, making them hydrophilic [12-14]. Li et al. (2014) demonstrated a three-component $\mathrm{CNT} / \mathrm{PPy} / \mathrm{MnO}_{2}$ sponge electrode with a controlled thickness and a shell sequence that was uniformly coated throughout the CNT sponge, maintaining the original CNT network and interconnections. A synergistic effect from the respective components ( $\mathrm{PPy}$, $\mathrm{MnO}_{2}$ ) and the porous conductive CNT network offers the hybrid sponge a superior electrochemical performance. The 3D CNT network significantly reduces the internal resistance of the electrode and maintains its structure stability. Porous CNT/PPy/ $\mathrm{MnO}_{2}$ sponges can serve as freestanding, compressible electrodes for supercapacitors as well as other energy devices [15].

Dhibar and Das (2014) synthesized a silver-polyaniline/ MWCNT [(Ag-PANI)/MWCNT] nanocomposite for highperformance supercapacitor electrodes. The possible interactions between Ag and PANI were characterized by Fouriertransform infrared (FT-IR) and UV/Visible spectroscopies. Morphological studies confirmed the formation of $\mathrm{Ag}$ nanoparticles in the PANI surface, and the MWCNTs were uniformly coated by PANI with the presence of Ag nanoparticles. The nanocomposite showed an improved electrical conductivity of $4.24 \mathrm{~S} \mathrm{~cm}^{-1}$ at room temperature and attained nonlinear current-voltage characteristics. The highest specific capacitance obtained for the nanocomposite was $528 \mathrm{Fg}^{-1}$. The nanocomposite also showed better energy and power densities. Ag-PANI/CNT-based supercapacitors with outstanding energy and power densities are a potentially promising candidate for future energy-storage systems [16].

Huo et al. (2013) synthesized three membrane electrodes for supercapacitors in microelectromechanical systems (MEMS), which were made of PPy, CNT/PPy, and graphene/PPy (GR/PPy) electrodeposited on Pt current collectors. Results indicate that there are strong adhesive forces between the electrode materials and the current collectors. The electrode resistances decrease in the order of $\mathrm{PPy}>\mathrm{CNT} /$ PPy $>$ GR/PPy. The specific capacitances are 7.0, 8.0, and $8.3 \mathrm{mF} \mathrm{cm}^{-2}$ at a discharge current of $1 \mathrm{~mA}$ and their retention rates after 5000 charge/discharge cycles are 72.9, 85.0, and 89.2\% for PPy, CNT/PPy, and GR/PPy, respectively [17].

$\mathrm{Hu}$ et al. (2012) demonstrated that CV scanning could be applied to effectively tailor the surface chemistry of CNTs and to introduce physical defects into the CNT walls, which drastically enhances the electrochemical capacitance performance of CNTs and their composites with PPy conducting polymer. As a consequence, the highest capacitance of $587 \mathrm{~F} \mathrm{~g}^{-1}$ was achieved among all of the tested samples, which is ten times higher than that of the defect-free counterparts. Electrochemical CV pretreatment provides an effective approach to activate the CNT surfaces for enhancing their electrochemical performance, meeting diverse demands and offering new pathways for designing and fabricating high-performance capacitance devices [18]. In previous work, we synthesized MWCNTs coated with protonated PANI, in situ, during the chemical polymerization of aniline. Uniform coating of CNTs with PANI was observed by scanning electron microscopy. An improvement in the covering of the CNT composites was found by the association of poly(2,5-dimercapto-1,3,4-thiadiazole) (PDMcT). A maximum conductivity of $96.8 \mathrm{~S} \mathrm{~cm}^{-1}$ has been found for a PANI/PDMcT/CNT composite. A high capacitance value $\left(289.4 \mathrm{~F} \mathrm{~g}^{-1}\right)$ was also determined for this composite, indicating that all materials, PANI, PDMcT, and CNT, remain active during charge/discharge cycling. The reduction in the capacitance after 100 cycles was found to be less than 25\% [19].

Thus, the objectives of this work were the synthesis of the $\mathrm{PPy} / \mathrm{CNT}$ composites by both chemical and electrochemical methods as well as their electrochemical, structural, and electrical characterization. The electrochemical performances of these electrochemical and chemical composites were tested for applications as electrodes in Type I supercapacitors, using both composites as electrodes with the same p-type doping.

\section{Experimental}

2.1. Functionalization of the MWCNTs. MWCNTs (Aldrich; diameter $110-170 \mathrm{~nm}$, length 5-9 $\mu \mathrm{m}$ ) were treated with $4 \mathrm{~mL}$ of a mixture of concentrated $\mathrm{HNO}_{3}$ and $\mathrm{H}_{2} \mathrm{SO}_{4}(1: 3 \mathrm{v} / \mathrm{v})$ at $50^{\circ} \mathrm{C}$ for $24 \mathrm{~h}$. In sequence, the functionalized CNTs were filtered and dried under vacuum [19]. For the composite synthesis, $50 \mathrm{mg}$ of CNTs was added to $20 \mathrm{~mL}$ of the synthesis solution of the polymer containing $0.025 \mathrm{~mol} \mathrm{~L}^{-1}$ sodium dodecyl sulfate (SDS). The mixture was dispersed ultrasonically for $3 \mathrm{~h}[19]$.

2.2. Physical Mixing of the CNTs with PPy. PPy powders were physically mixed with CNTs in a CNT/PPy ratio of $20: 80$ (wt/wt).

2.3. Chemical Synthesis of the PPy/CNT Composite and $P P y$. For the composite synthesis, the pyrrole monomer $\left(0.1 \mathrm{~mol} \mathrm{~L}^{-1}\right)$ was added to $20 \mathrm{~mL}$ of $\mathrm{NaCl}\left(3 \mathrm{~mol} \mathrm{~L}^{-1}\right)$ and $\mathrm{HCl}$ aqueous solution $\left(1 \mathrm{~mol} \mathrm{~L}^{-1}\right)$ containing $50 \mathrm{mg}$ of dispersed CNTs. A solution of $\mathrm{FeCl}_{3}\left(0.0022 \mathrm{~mol} \mathrm{~L}^{-1}\right)$ in $\mathrm{NaCl}$ $\left(3 \mathrm{~mol} \mathrm{~L}^{-1}\right) / \mathrm{HCl}\left(1 \mathrm{~mol} \mathrm{~L}^{-1}\right)$ was added $(20 \mathrm{~mL})$ to the reaction medium for $2 \mathrm{~h}$, maintaining the temperature at $-10^{\circ} \mathrm{C}$ in order to secure a higher ordering of the polymer backbone. The precipitate was collected by filtration and then washed with $1 \mathrm{~L}$ of $1 \mathrm{~mol} \mathrm{~L}^{-1} \mathrm{HCl}$, obtaining the conducting state of the PPy/CNTs, which was then dried under a dynamic vacuum for $48 \mathrm{~h}$. The PPy was synthesized under the same conditions.

2.4. Electrochemical Synthesis of the PPy/CNT Composite and $P P y / P t$. For all electrochemical syntheses of the composites and PPy, conventional electrochemical cells were used, 
comprising three electrodes: a working electrode, a platinum counter electrode, and a $\mathrm{Ag} / \mathrm{AgCl}_{\text {(sat.) }}$ reference electrode. All electrochemical measurements were performed using a PGSTAT30 Autolab potentiostat.

To prepare the CNT/Pt films, the CNT powder was added to $10 \%(\mathrm{w} / \mathrm{w}) \mathrm{PVDF}$ in cyclopentanone. The mixture was heated to $120^{\circ} \mathrm{C}$ to acquire a gelatinous consistency. Then, the platinum was painted with the gel containing the CNTs and, subsequently, it was heated to $60^{\circ} \mathrm{C}$ for $20 \mathrm{~min}$ in order to evaporate the solvent. Then, $\mathrm{CV}$ was performed on the CNT film on Pt to ensure that the anodic charge was about $5 \pm 1 \mathrm{mC}$. The anodic films that had anodic charges that were higher or lower than $5 \pm 1 \mathrm{mC}$ were discarded.

The electrochemical synthesis of the PPy/CNT binary composite was realized by chronoamperometry at $0.8 \mathrm{~V}$ (versus $\left.\mathrm{Ag} / \mathrm{AgCl}_{(\text {sat.) }}\right)$ up to an anodic charge of $130 \mathrm{mC}$ on the CNT films $(5.9 \mathrm{mC}$ ) in $20 \mathrm{~mL}$ acetonitrile (HPLC grade), which contained $0.1 \mathrm{~mol} \mathrm{~L}^{-1}$ distilled pyrrole, $2 \%$ deionized $\mathrm{H}_{2} \mathrm{O}$, and $0.1 \mathrm{~mol} \mathrm{~L}^{-1} \mathrm{LiClO}_{4}$. The PPy/Pt was synthesized under the same conditions $[21,22]$.

2.5. Structural Characterization by FT-IR Spectroscopy. FTIR spectroscopy was performed using an infrared spectrophotometer (ABB BOMEM MB series) using pellets of the composite powder containing $\mathrm{KBr}(1: 100)$ from 400 to $4000 \mathrm{~cm}^{-1}$.

2.6. Characterization by XRD Analysis. The powders were also characterized by X-ray diffraction (XRD) using a Shimadzu diffractometer (Model 6000, radiation $\mathrm{CuK} \alpha, \lambda=$ $1.5406 \AA$ Á) with a voltage of $40 \mathrm{kV}$, a current of $30 \mathrm{~mA}$, at $2 \theta \mathrm{min}^{-1}$, and within the of $5^{\circ} \leq 2 \theta \leq 70^{\circ}$ range.

2.7. Morphological Characterization by SEM. SEM images were obtained using a Hitachi electronic scanning microscope, Model 3000, enlarging the images 15000 times with acceleration voltages of 5 and $10 \mathrm{kV}$.

\subsection{Electrochemical Stability of the PPy/CNT Composites and} Constituent Materials: $C V$. The electrochemical stabilities of the chemical and electrochemical PPy/CNT composites were evaluated by $\mathrm{CV}$ from -0.2 to $0.8 \mathrm{~V}$ (versus $\mathrm{Ag} / \mathrm{AgCl}_{(\text {sat.) }}$ ) at $100 \mathrm{mV} \mathrm{s}^{-1}$ in ethylene carbonate (EC) and dimethyl carbonate (DMC) $(50 \% \mathrm{v} / \mathrm{v})$ containing $1 \mathrm{~mol} \mathrm{~L}^{-1} \mathrm{LiClO}_{4}$ for 100 consecutive cycles.

2.9. Characterization of the PPy/CNT Composites and Constituent Materials: EIS. Electrochemical impedance spectroscopy (EIS) spectra were recorded by applying of alternating current $(\mathrm{AC})$ amplitude of $10 \mathrm{mV}$, and the data were collected in the frequency range from $10^{-3}$ to $10^{4} \mathrm{~Hz}$. All electrochemical experiments were realized in an Autolab PGSTAT 20 FRA instrument.

2.10. Charge and Discharge Tests of the Devices: Galvanostatic Chronopotentiometry. Before the charge and discharge tests, $\mathrm{CV}$ was performed to select the electrodes that had similar anodic charges, which could then be used as working, reference, and counter electrodes to characterize a Type I supercapacitor (same materials with similar p-type doping).

The electrochemical characterization of the chemical and electrochemical composites was performed over five $\mathrm{CV}$ scans in EC/DMC (50\% v/v) containing $1 \mathrm{~mol} \mathrm{~L}^{-1} \mathrm{LiClO}_{4}$ at $100 \mathrm{mV} \mathrm{s}^{-1}$, using $\mathrm{Ag} / \mathrm{AgCl}_{\text {(sat.) }}$ as the reference electrode, platinum as the counter electrode, and the composites as working electrodes. This electrochemical characterization aimed to select the composites that had similar anodic charges in order to be tested as electrodes in Type I supercapacitors. Charge and discharge tests were conducted at different current densities for each conducting composite and their constituent materials, such as $1.0 \mathrm{~mA} \mathrm{~cm}^{-2}$ for the electrochemically synthesized PPy/CNT composite and $0.1 \mathrm{~mA} \mathrm{~cm}^{-2}$ for the chemically synthesized PPy/CNT composite in the potential range from -0.79 to $0.49 \mathrm{~V}$.

\section{Results and Discussion}

3.1. Electropolymerization of PPy and the PPy/CNT Composite. The electropolymerization of the PPy on CNT/Pt and PPy/Pt was realized by chronoamperometry (Figures 1(a) and 1(b)). The anodic charge was set at $130 \mathrm{mC} \pm 10 \mathrm{mC}$. In the chronoamperogram of the PPy/CNT composite (shown in Figure 1(a)) it is observed that current density for the anodic polypyrrole on $\mathrm{Pt}$ (no growth restriction) is much lower than that obtained for polypyrrole on CNT/Pt (with growth restriction). Therefore, the elapsed time for $\mathrm{PPy} / \mathrm{Pt}$ achieving the desired anodic charge was much higher than that obtained for the PPy/CNT composite (growth restriction). So this was an indication that the electronic conductivity of the PPy/CNT composite (with growth restriction) was higher than for those obtained for $\mathrm{PPy} / \mathrm{Pt}$ (no growth restriction). This occurs due to the formation of branching in the chain of PPy grown on $\mathrm{Pt}$ which compromises its electronic conductivity. Already the CNTs act as a host matrix for the polypyrrole, determining its shape, size, and spatial arrangement, thus fostering growth linearly, favoring the electronic conductivity of the resulting film.

In Figure 1(b) is an inset of the chronoamperogram for polymerized PPy on Pt. The chronoamperogram shows welldefined regions, that is, a decrease in the current values, which can be attributed to the electric double layer, and an increase in the current density as a function of time, corresponding to nucleation and another constant for the growth of the conducting polymer [22].

3.2. Structural Characterization by FT-IR. Structural characterization of the composites and their constituent materials was performed by FT-IR (Figure 2). The FT-IR spectrum of the CNTs shows a broad band at $3460 \mathrm{~cm}^{-1}$, assigned to the $\mathrm{OH}$ stretching, and an intense band at $1633 \mathrm{~cm}^{-1}$, corresponding to $\mathrm{C}=\mathrm{O}$ stretching from the carboxylic acid incorporated into the CNTs after functionalization in acid medium [22].

Already, the FT-IR of the PPy shows a vibrational C-N stretching band at $1404 \mathrm{~cm}^{-1}$ from the aromatic amine groups 


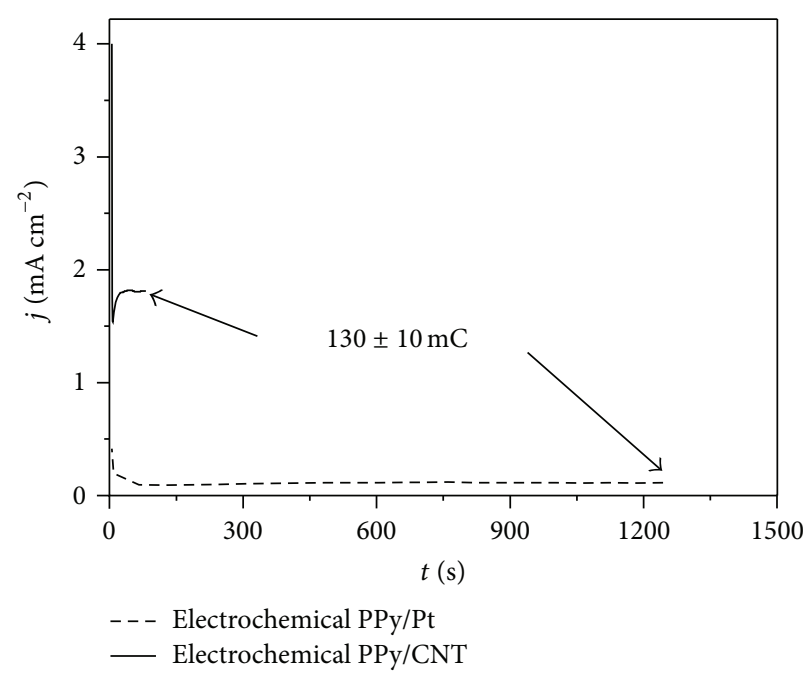

(a)

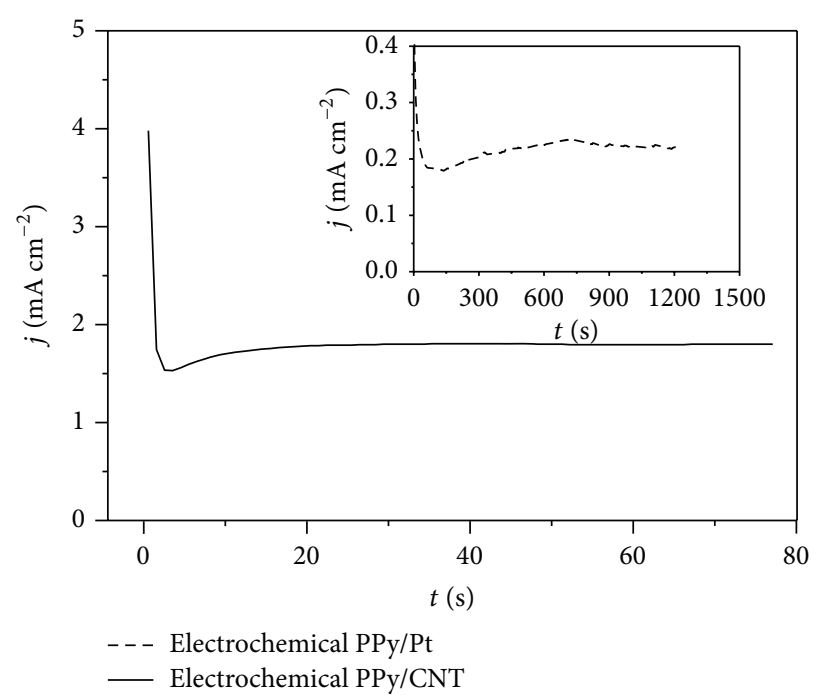

(b)

Figure 1: Chronoamperograms of the (a) PPy/Pt and PPy/CNTs electrochemically synthetized in acetonitrile (HPLC grade), $2 \% \mathrm{H}_{2} \mathrm{O}$ (deionized), and $0.1 \mathrm{~mol} \mathrm{~L}^{-1} \mathrm{LiClO}_{4}$ at $0.8 \mathrm{~V}$. (b) Inset of the chronoamperogram for PPy on Pt.

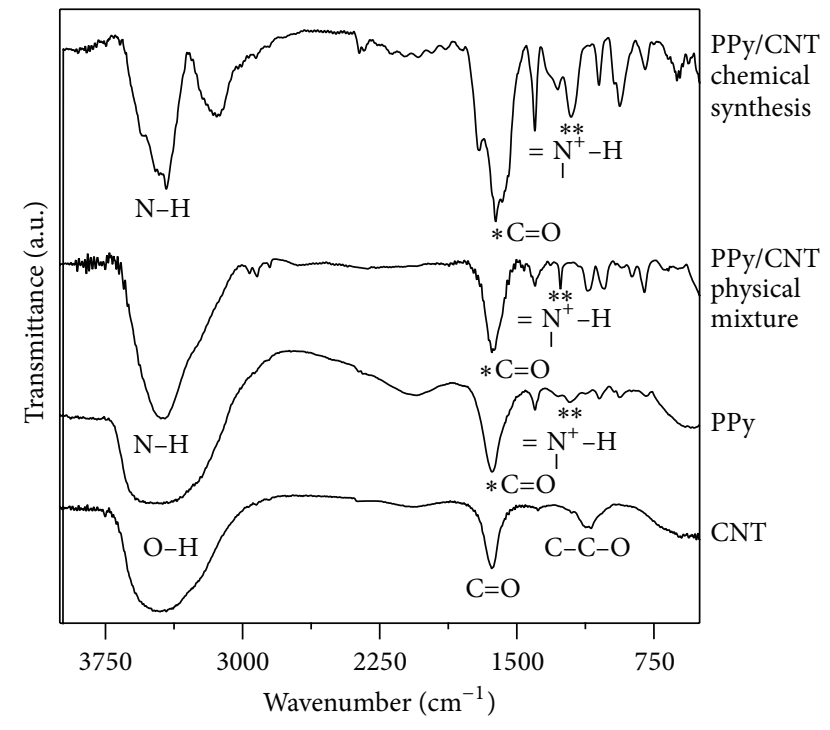

FIGURE 2: FT-IR spectra of PPy, CNTs, physical mixture of $\mathrm{PPy} / \mathrm{CNTs}$, and chemically synthesized PPy/CNT composite.

and a second vibrational $\mathrm{C}-\mathrm{H}$ stretching band between 1402 and $1047 \mathrm{~cm}^{-1}$. The bands that appear in the 3000 to $3750 \mathrm{~cm}^{-1}$ region are related to $\mathrm{N}-\mathrm{H}$ stretching in different environments [23]. The band at $1201 \mathrm{~cm}^{-1}$ can be associated with $-\mathrm{NH}^{+}=$stretching. The authors interpreted this stretch to originate from the bipolaronic structure, evidencing the presence of PPy in its conducting form when the PPy was chemically synthesized [24]. In addition, it is observed that the FT-IR spectrum of PPy/CNTs exhibits a peak at $1614 \mathrm{~cm}^{-1}$, which refers to the association of the $\mathrm{C}-\mathrm{C}$ and $\mathrm{C}=\mathrm{O}$ vibrations in the CNTs. Thus, from this FT-IR analysis, it is possible to infer that the $\mathrm{PPy} / \mathrm{CNT}$ composite was successfully synthesized.

The CNTs were physically mixed with the PPy powder in the ratio $(2: 8 \mathrm{w} / \mathrm{w})$ in order to compare its IR spectrum with that obtained for the chemically synthesized composite. It was observed that the spectrum of the chemically synthesized composite presented $\mathrm{O}-\mathrm{H}$ stretching, which was slightly shifted from $1637 \mathrm{~cm}^{-1}$ (spectra of PPy and physical composite) to $1614 \mathrm{~cm}^{-1}$. This displacement and the intensification of the band at $1197 \mathrm{~cm}^{-1}$ indicated a higher degree of oxidation of the PPy present in the composite compared to PPy in the physically mixed constituent materials. The presence of carboxylic groups on the CNT surface (band at $1614 \mathrm{~cm}^{-1}$ ) is likely to result in interfacial interactions between the polymer and the CNTs. This is attributed to the hydrogen bonds, which were formed between - $\mathrm{COOH}$ groups in chemically modified CNTs and $=\mathrm{NH}^{+}$groups of PPy [20], as shown in Figure 3.

3.3. Characterization by XRD. The composites were also characterized by XRD. The XRD pattern of the CNTs shows a diffraction peak at $26.4^{\circ}$, which is assigned to the graphitic structure present in the CNTs, and other diffraction peaks are attributed to impurities during the manufacturing process of the CNTs (Figure 4). The XRD pattern of PPy presented broad diffraction peaks at $2 \theta=22.9^{\circ}$, owing to the pyrrole intermolecular spacing [25]. Besides, in the XRD pattern of the chemical Ppy/CNT composite, it was observed that, when the CNTs were embedded into the PPY matrix, the peak at $2 \theta$ $=21^{\circ}$ becomes broader and weaker, possibly because of the superimposition of peaks of the CNTs with a large band of the PPy. The results from XRD analysis support the presence of PPy and CNTs in the composite. 


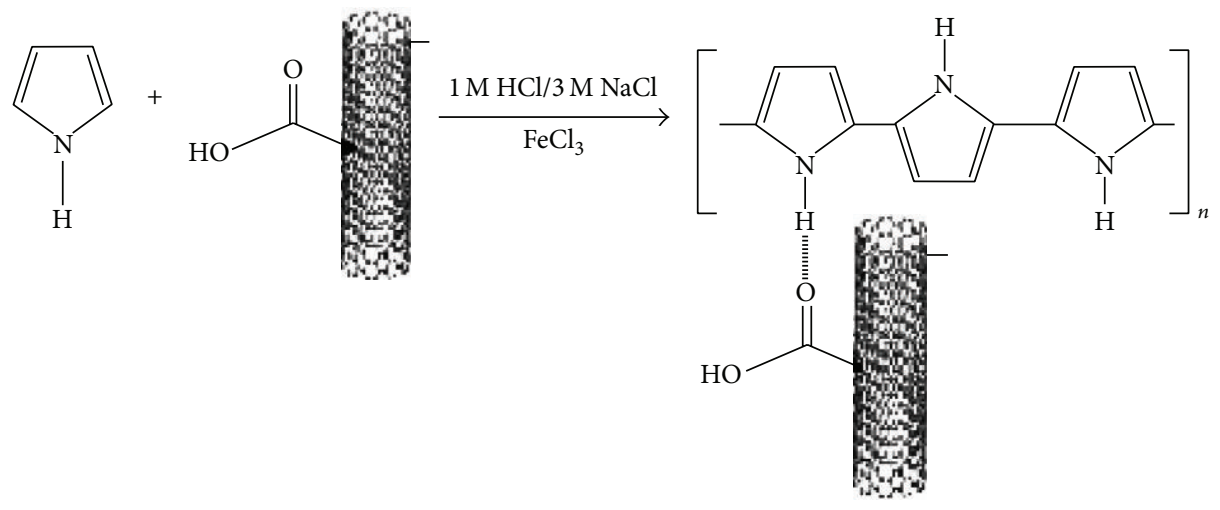

FIgURE 3: Polymerization mechanism of PPy on the CNTs (adapted from [20]).

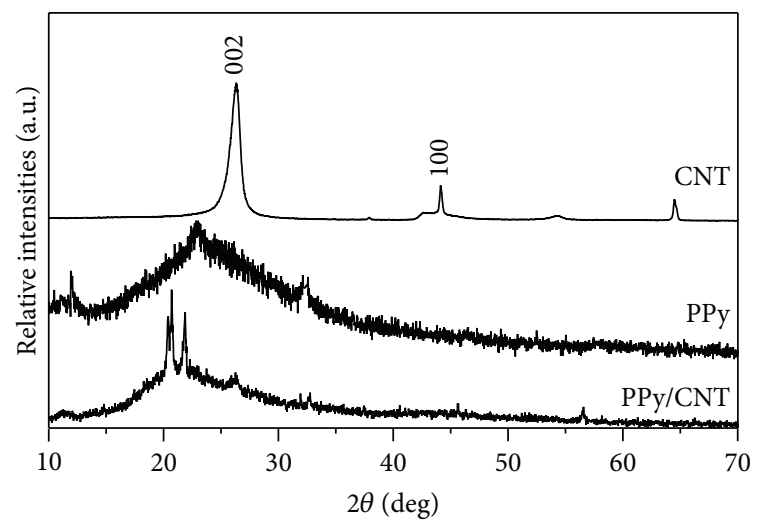

FIGURE 4: XRD patterns of the chemically synthesized PPy/CNT composite, CNTs, and PPy.

The relative intensities of these reflections are sensitive to the ring-tilt angle and they are attributed to the $\mathrm{Cl}-\mathrm{N}$ distance, which is related to the doping level in PPy [20].

3.4. Morphological Characterization by SEM. The SEM image of the CNTs showed homogeneously scattered beams (Figure 5(a)). Figure 5(b) shows a typical morphology of PPy. The particle size of PPy was $0.85-4.16 \mu \mathrm{m}$, with spherical morphology. Based on the interaction between pyrrole monomers and CNTs, the pyrrole molecules were adsorbed and polymerized on the surface of the CNTs. This process is confirmed by the SEM image of the composite. Pyrrole molecules were adsorbed and polymerized on the surface of the CNTs, which were wrapped by PPy (Figure 5(c)), corroborating the FT-IR data (Figure 2). Therefore, it is predicted that, in the presence of CNTs, PPy could grow around the CNTs and encapsulate them. Compared with the CNTs, the diameter of the CNT/PPy composite increased from $200 \pm 10 \mathrm{~nm}$ to $550 \pm 10 \mathrm{~nm}$, and the external surface became more rough. This morphology is in agreement with the SEM image shown for PPy coated MWNTs, which were synthesized by Sahoo et al. in 2007 [20]. Besides, polypyrrole networks interconnecting nanotubes are not observed. The
TABLE 1: Charge-transfer resistance $\left(R_{\mathrm{ct}}\right)$ values of the electrochemical and chemical PPy/CNT composites and their constituent materials.

\begin{tabular}{lc}
\hline Materials & $R_{\mathrm{ct}} / \Omega \mathrm{cm}^{-2}$ \\
\hline Electrochemical PPy/CNT composite & 1.0 \\
Chemical PPy/CNT composite & 4.5 \\
PPy & 5.5 \\
CNTs & 7.5 \\
\hline
\end{tabular}

absence of such polymeric networks indicates that there was a limited growth of polypyrrole inside and around the CNTs.

It was not possible to realize the morphological characterization of the electrochemical PPy/CNT composite, owing to the formation of a very thin film that adhered to the platinum. In the X-ray diffuse scattering (XDS) spectrum, the presence of $11.7 \mathrm{wt} \%$ of $\mathrm{Cl}$ was observed, indicating that the pyrrole was polymerized on the CNTs in its conducting form and that the counter ions from the electrolyte (chloride ions) neutralized the positive charge density of the formed polymer (Figure 6). Then, the PPy was chemically synthesized on the CNTs.

3.5. Electrical Characterization by EIS. After structural characterization, the electrical characterization of the PPy/CNT composites and their constituent materials was realized by EIS. Nyquist diagrams for all of the films are shown in Figure 7, where the inset of Figures 7(a) and 7(c) presents the high- and medium-frequency regions for better visualization of the electrochemical processes in Figures $7(\mathrm{~b})$ and 7(d), respectively. The Nyquist diagrams of PPy and the CNTs showed high impedance values compared with those obtained for the electrochemical and chemical CNT/PPy composites. The curves obtained for the composites also showed a deviation in slope from a vertical position in relation to the CNTs and PPy, which is attributed to the low charge-transfer resistance $\left(R_{\mathrm{ct}}\right)$ values and may be attributed to the high porosity and mobility of protons inside the electrodes or a combination of these factors. This favored electronic transfer in the conducting composite, thus drastically reducing the $R_{\mathrm{ct}}$ value, making them more capacitive, as shown in Table 1 [26]. The electrochemically 


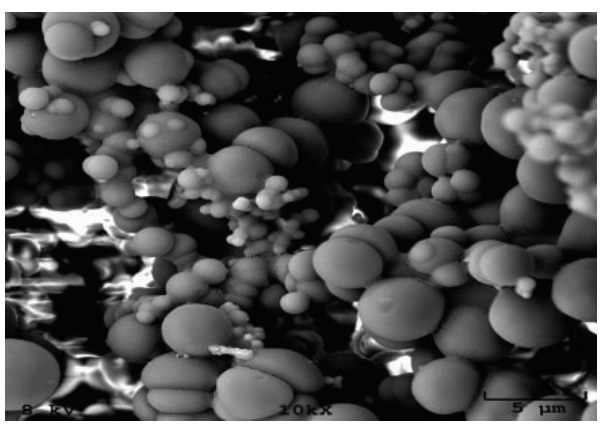

(a)

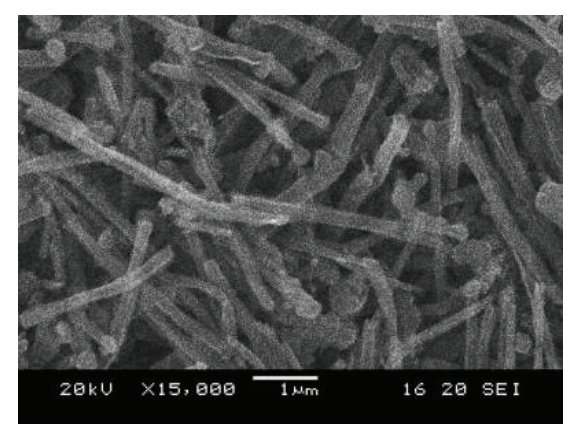

(b)

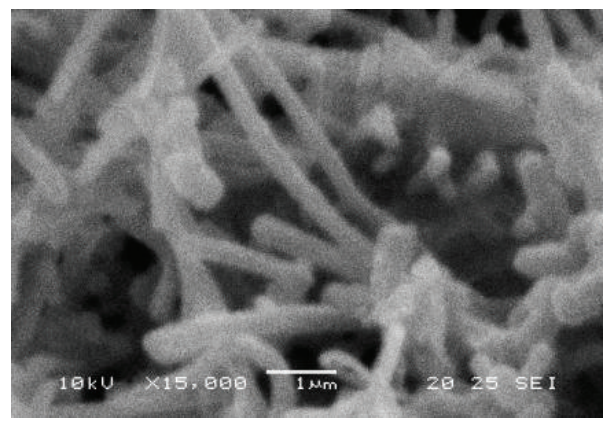

(c)

Figure 5: SEM images of (a) PPy, (b) CNTs, and (c) chemical CNT/PPy composite.

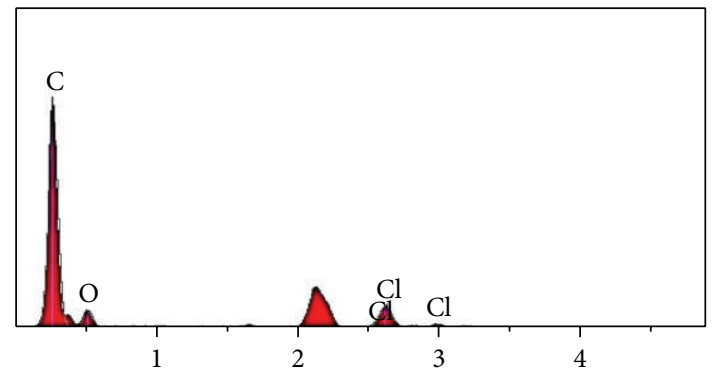

FIGURE 6: XDS spectrum of the chemical CNT/PPy composite.

synthesized PPy/CNT composite showed the lowest $R_{\mathrm{ct}}$ value $\left(1.0 \Omega \mathrm{cm}^{-2}\right)$ when compared with other materials (Figure 7(d) and Table 1) and presented a predominately capacitive profile (Figure 7(a)). Then, the increase in electron transfer in this conducting composite is perhaps attributable to the dopant effect or charge transfer from PPy to the CNTs. CNTs are relatively good electron accepters, whereas PPy can be considered a good electron donor. This can be partially proven by the FT-IR spectrum, which suggests delocalization of electrons in the composite. Also, owing to the large aspect ratio and surface area of CNTs, they may serve as "conducting bridges," connecting conducting PPy domains [27] and resulting in higher conductivity, thus lowering the $R_{\mathrm{ct}}$ values obtained for these composites [28] (see Figure 7(d) and Table 1). Interestingly, both the electrochemical and chemical composites presented Nyquist diagrams with angles between the decline lines and the real axes larger than $45^{\circ}$ and lower than $90^{\circ}$ (Figures $7(\mathrm{a})$ and $7(\mathrm{~b})$ ), corresponding to the ion-diffusion mechanism between Warburg diffusion and ideal capacitive ion-diffusion. In addition, it is found that the two decline slopes for the composites are close to each other at low frequencies, implying that both doped and undoped states of PPy are present in the composite, which have similar geometric capacitance. This profile demonstrates its application as an electrode in Type I supercapacitors.

From the Nyquist diagrams of the electrochemical and chemical PPy/CNT composites and their constituent materials (Figures 7(b) and 7(d)), the extrapolation of the semicircle was held in high frequency region in order to obtain the charge transfer resistance whose values are shown in Table 1.

As the chemical and electrochemical PPy/CNT composites presented the lowest $R_{\mathrm{ct}}$ values and capacitive behavior, they were tested as electrodes in Type I supercapacitors using cyclic voltammetry and galvanostatic chronopotentiometry.

3.6. Electrochemical Stability by Cyclic Voltammetry. The electrochemical stability of the composites was evaluated by $\mathrm{CV}$ (versus $\mathrm{Ag} / \mathrm{AgCl}_{\text {(sat.) }}$ ) for 100 consecutive cycles. Figure 8 shows the cyclic voltammograms at 25, 50, 75, and 100 cycles, corresponding to the stability tests of the electrochemical and chemical PPy/CNT composites. Both composites presented current density values that were practically constant. In the cyclic voltammograms (Figures 8(a) and 8(b)), higher current density values were observed for the electrochemical composite than for the chemical composites. The electrochemical composites presented a total charge of around $45 \mathrm{mC}$ and the chemical composite was only $2.5 \mathrm{mC}$, showing a higher 


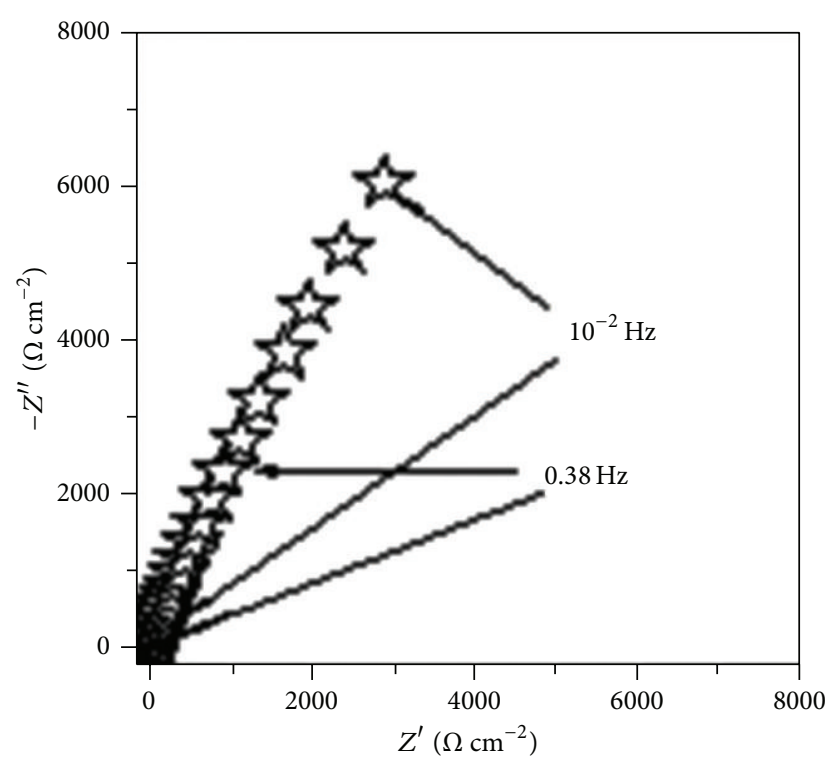

Electrochemical PPy/CNT

is Chemical PPy/CNT

(a)

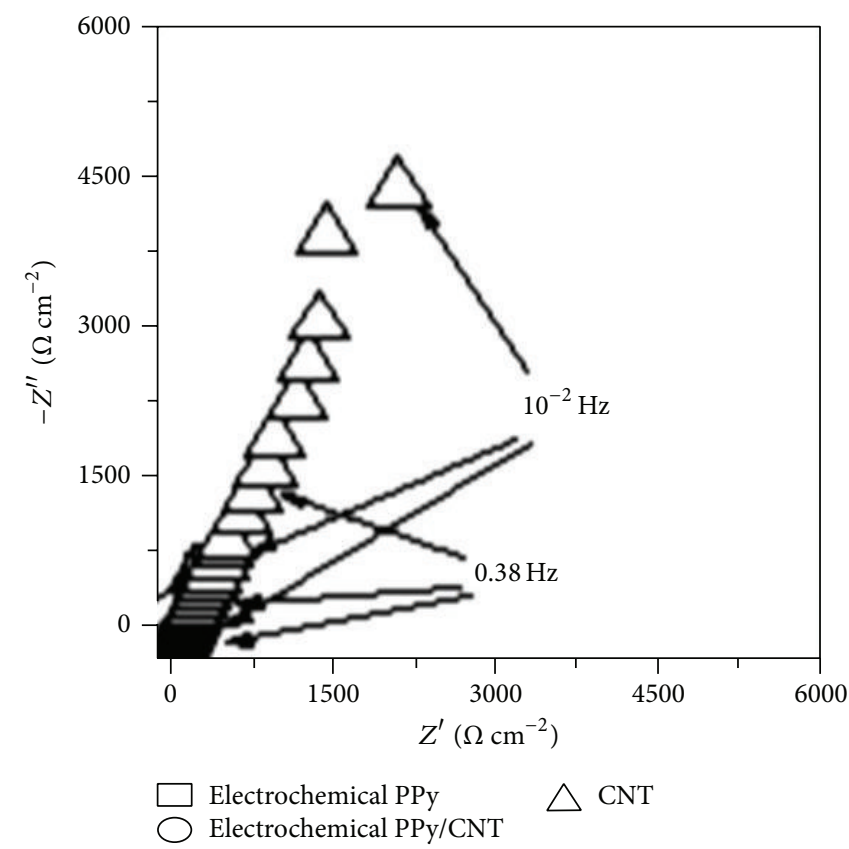

(c)

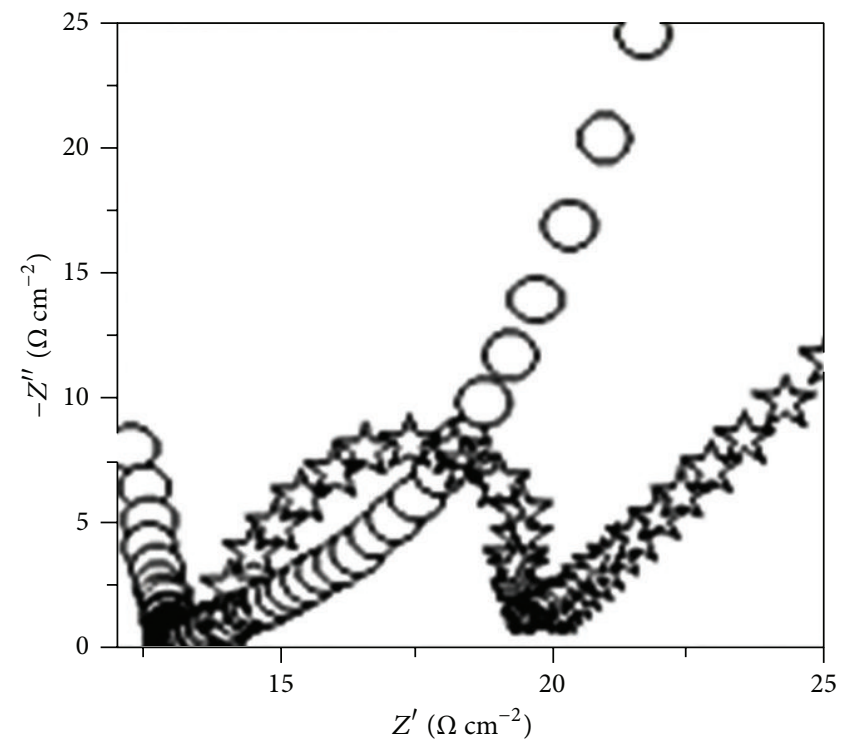

O Electrochemical PPy/CNT

is Chemical PPy/CNT

(b)

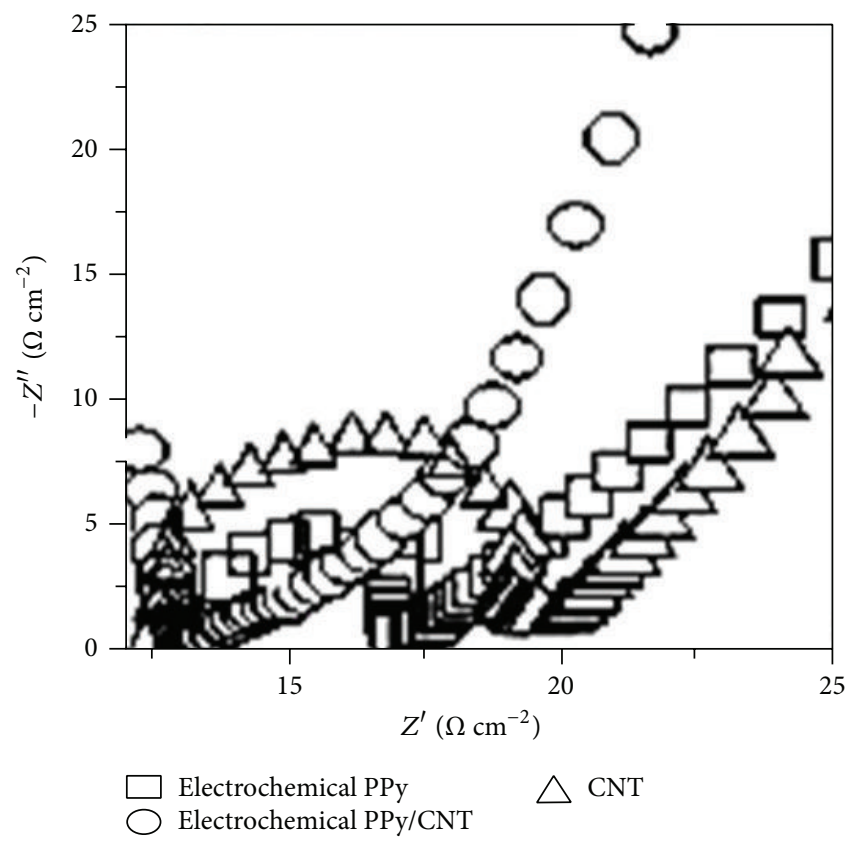

(d)

FIGURE 7: Nyquist plots of the (a) electrochemical and chemical PPy/CNT composites; (b) inset of the Nyquist diagram of the electrochemical and chemical PPy/CNT composites in high frequency region; (c) Nyquist diagram of the electrochemical composite and its constituent materials; and (d) inset of the Nyquist diagram of the electrochemical composite and its constituent materials in high frequency region in EC/DMC (50\% v/v) containing $1 \mathrm{~mol} \mathrm{~L}^{-1} \mathrm{LiClO}_{4}$.

synergic effect between the constituent materials in the composite synthesized through electrochemistry.

In the electrochemical stability tests of the electrochemically synthesized PPy/CNT composite and its constituent materials, after the 100th cycle (in Figures 9(a) and 9(b)), both composites presented current density values and, consequently, total charges that were higher than those obtained for their constituent materials. In addition, the current density values of the electrochemical composite were higher than those obtained for chemical composite (Figures 9(a) and 9(b)). This shows that, during chemical synthesis, there was no tight control on the growth of the PPy 


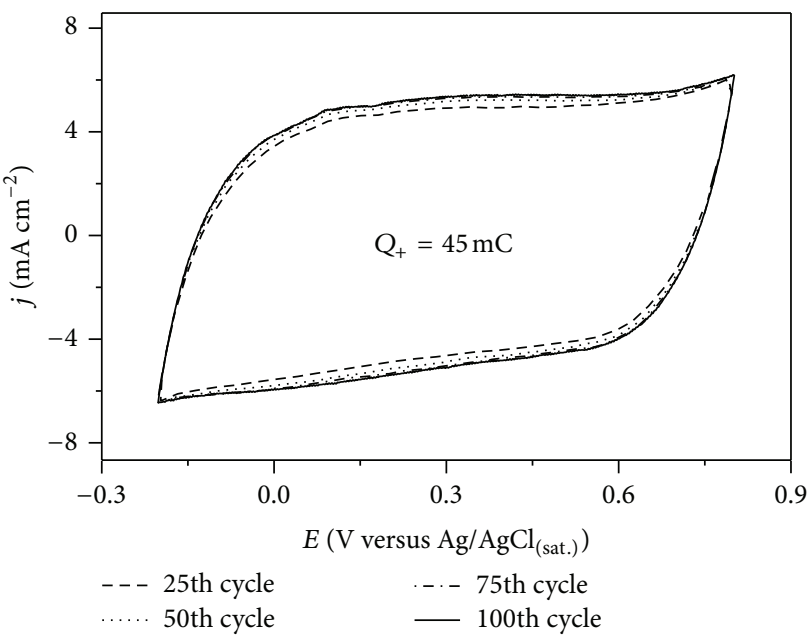

(a)

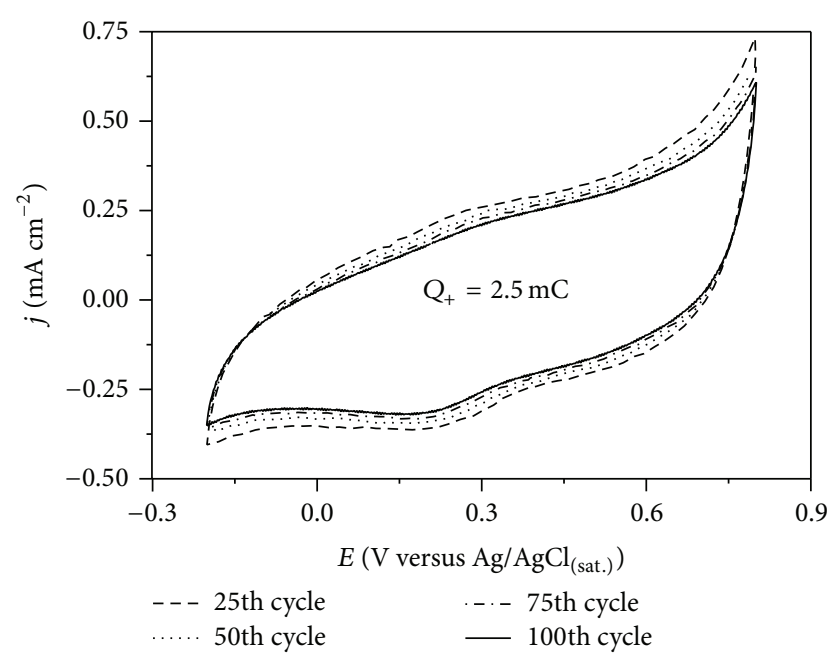

(b)

FIGURE 8: Cyclic voltammograms corresponding to the electrochemical stability tests of (a) the electrochemically synthesized PPy/CNT composite and (b) the chemically synthesized PPy/CNT composite in EC/DMC (50\% v/v), containing $1 \mathrm{~mol} \mathrm{~L}^{-1} \mathrm{LiClO}_{4}$, at $100 \mathrm{mV} \mathrm{s}^{-1}$.

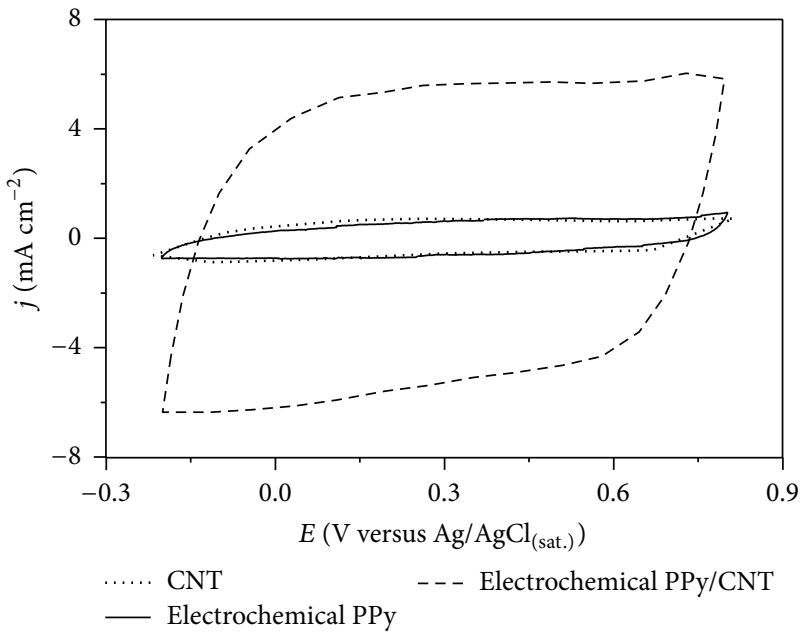

(a)

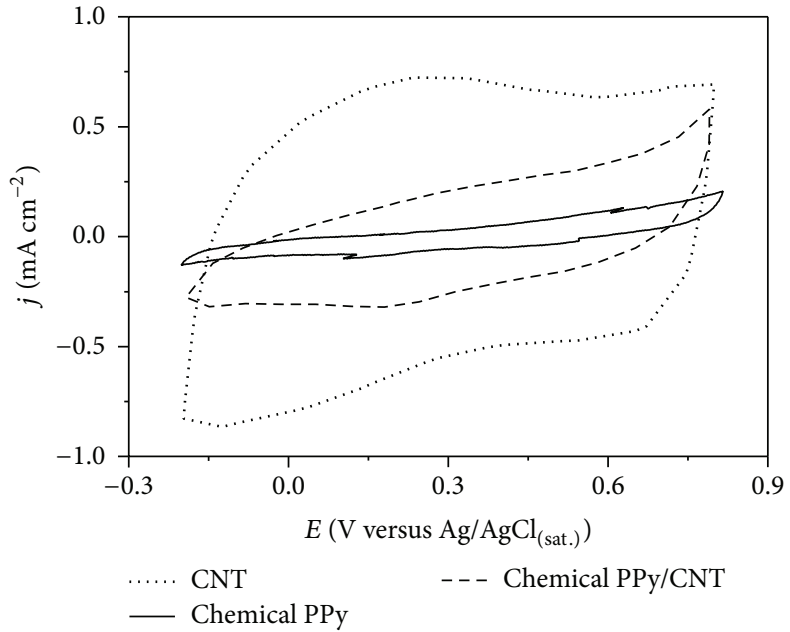

(b)

Figure 9: Cyclic voltammograms (100th cycle) realized in EC/DMC ( $50 \% \mathrm{v} / \mathrm{v})$, containing $1 \mathrm{~mol} \mathrm{~L}^{-1} \mathrm{LiClO}_{4}$, at $100 \mathrm{mV} \mathrm{s}^{-1}$ for $(\mathrm{a})$ the electrochemical PPy/CNT composite and constituent materials and (b) the chemical PPy/CNT composite and constituent materials.

film during the polymerization reaction. Then, undesirable functional groups and probable ramifications become present in the polymeric chain, which may compromise the electronic conductivity of the chemical composite and of the PPy [29, 30]. In the electrochemical synthesis, the polymerization of the PPy was controlled by application of a specified potential range, resulting in an ordered polymeric bone, which may have grown on the CNTs as well as into the CNTs, favoring the formation of a composite with higher electronic conductivity values (Figure 9).

Figure 10 exhibits the voltammetric profiles of the chemical, electrochemical, and physical composites. The electrochemical composite presented the highest total charge and a voltammetric profile more capacitive than those obtained for the chemical and physical composites. Furthermore, both the electrochemical and chemical composites presented current density values higher than that obtained for the physical composite, indicating a probable interaction between its constituent materials (PPy and CNTs), which favors the electronic conductivity of these composites. However, the electrochemical composite had a more capacitive and less resistive behavior than that obtained for chemical composite.

Electrochemical tests of the devices containing chemical and electrochemical PPy/CNT composites were measured on the basis of two-electrode using cyclic voltammetry, galvanostatic chronopotentiometry, and electrochemical impedance spectroscopy. This enabled those with similar anodic charges to be selected for subsequent testing as electrodes in Type 


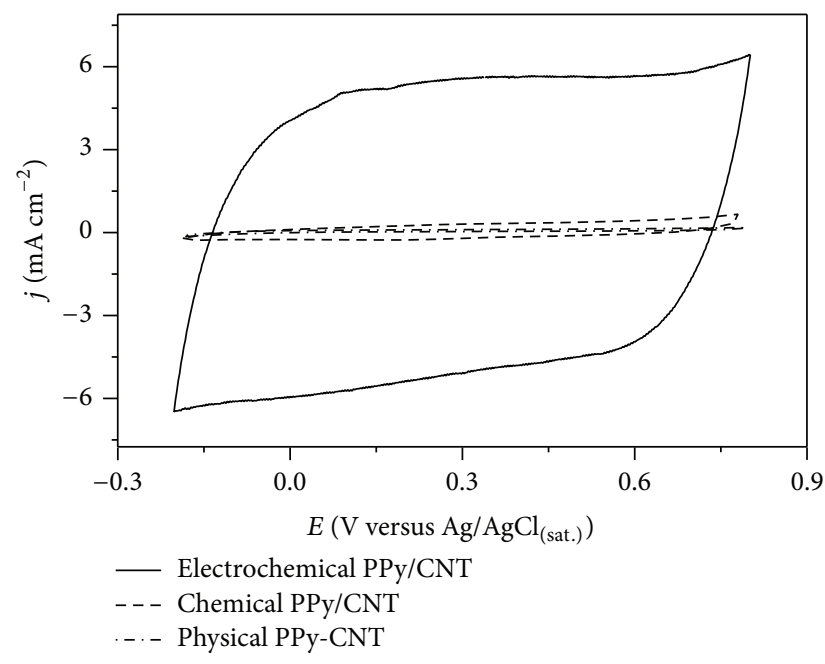

(a)

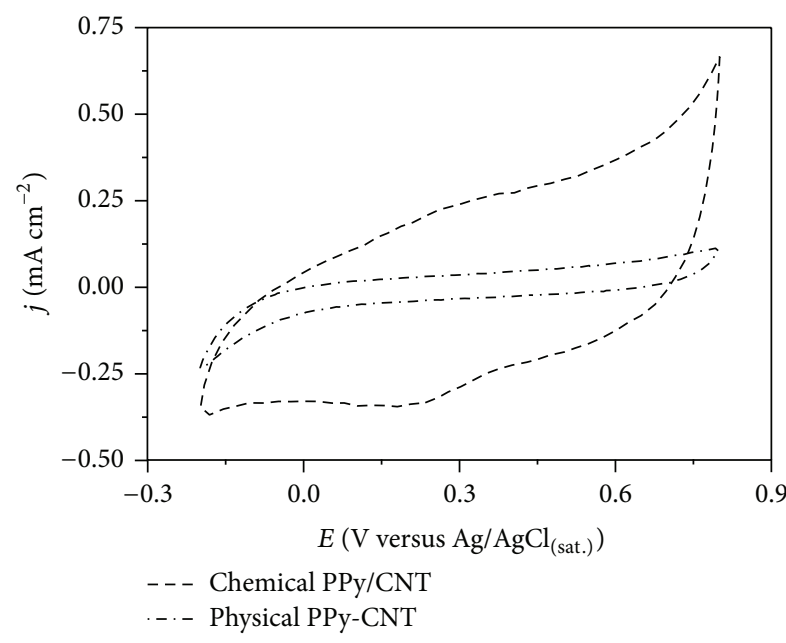

(b)

Figure 10: (a) Cyclic voltammograms (100th cycle) realized in EC/DMC (50\% v/v), containing $1 \mathrm{~mol} \mathrm{~L}^{-1} \mathrm{LiClO}_{4}$, at $100 \mathrm{mV} \mathrm{s}^{-1}$ for $(\mathrm{a})$ the electrochemical PPy/CNT composite, the chemical PPy/CNT composite, and the physical PPy/CNT mixture. (b) Cyclic voltammograms of the chemical PPy/CNT composite and physical PPy-CNT mixture.

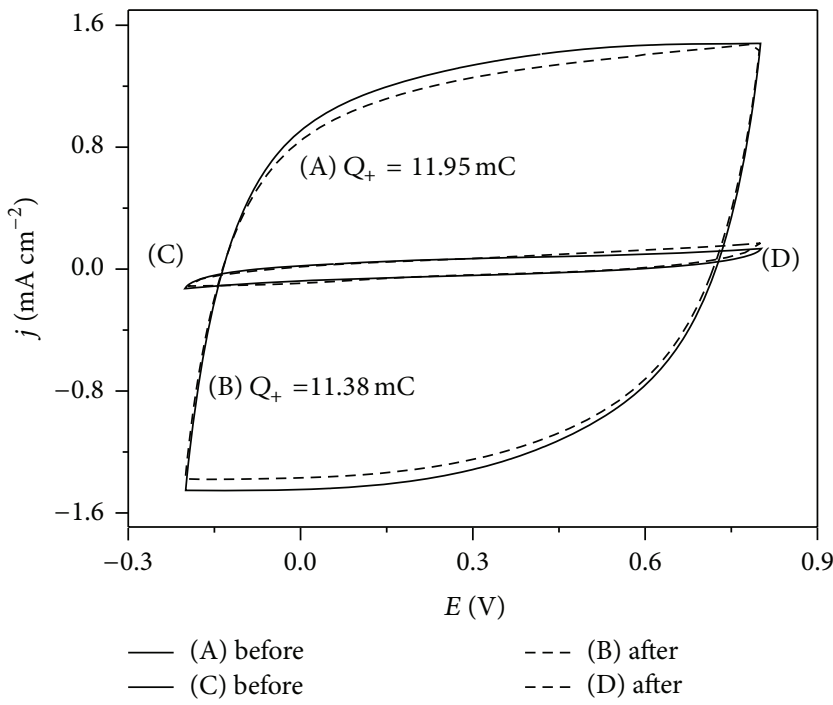

(a)

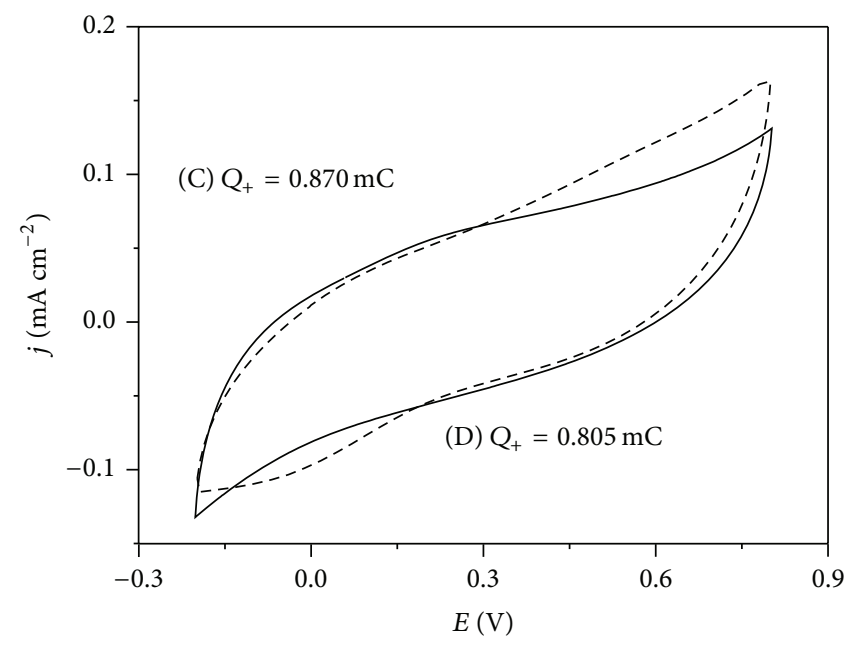

(C) before
$---(D)$ after

(b)

FIGURE 11: (a) Cyclic voltammograms (five cycles) conducted in EC/DMC (50\% v/v), containing $1 \mathrm{~mol} \mathrm{~L}^{-1} \mathrm{LiClO}_{4}$, at $100 \mathrm{mV} \mathrm{s}^{-1}$ for the electrochemical PPy/CNT composite ((A) is the device before and (B) is the device after charge and discharge tests) and the chemical $\mathrm{PPy} / \mathrm{CNT}$ composite $((\mathrm{C})$ is the device before and (D) is the device after charge and discharge tests). (b) Amplification of the chemical composite device ((C) and (D)) before and after the charge and discharge tests.

I supercapacitors (same materials with similar p-doping) (Figure 11). In the cyclic voltammograms of the electrochemical PPy/CNT composite device, the same behavior was observed as for the composite electrodes (Figure 8). The cyclic voltammogram presented an almost constant total charge around $11.38 \mathrm{mC}$ after 50 charge and discharge cycles, indicating good redox reversibility (Figure 11(a)). In addition, it was found that the two CV curves almost overlapped, which implied that there was almost no geometric capacitance degeneration after five cycles. Therefore, the prepared $\mathrm{PPy} / \mathrm{CNT}$ composite has stable cyclic behavior [31].
The cyclic voltammograms for the chemical PPy/CNT composite exhibited the lowest total charge $(0.805 \mathrm{mC})$ after the charge and discharge tests (Figure 11(b)). The decrease in the values of the total charge compared to the values obtained for chemical and electrochemical composites (versus $\left.\mathrm{Ag} / \mathrm{AgCl}_{\text {(sat.) }}\right)$ is attributed to the lack of electrochemical activation of the electrodes when they were submitted to repeated cycling.

The composite electrodes were tested as electrodes in Type I supercapacitors (same material with same doping type) using the galvanostatic chronoamperometry method 


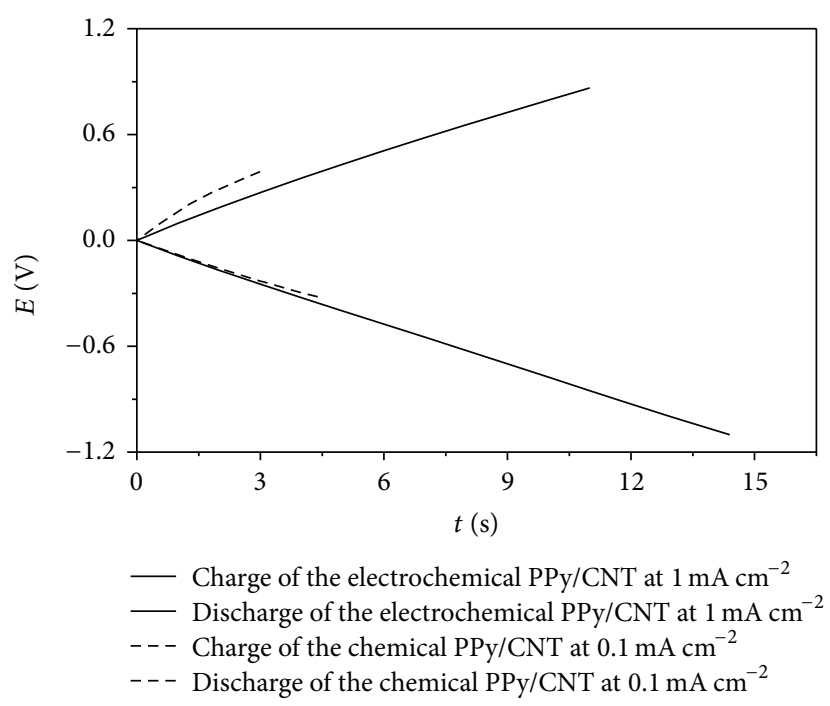

(a)

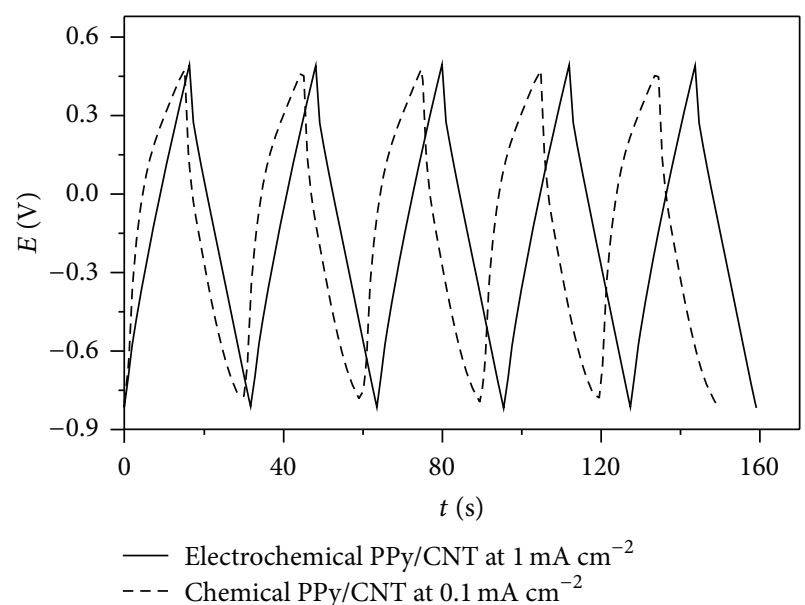

(b)

Figure 12: Charge and discharge curves of electrochemical and chemical PPy/CNT composites in EC/DMC (50\%v/v) containing $1 \mathrm{~mol} \mathrm{~L}^{-1} \mathrm{LiClO}_{4}$. The current densities of the composites and their constituent materials were $1.0 \mathrm{mAcm}^{-2}$ for the electrochemically synthesized PPy/CNT composite and $0.1 \mathrm{~mA} \mathrm{~cm}^{-2}$ for the chemically synthesized PPy/CNT composite.

(Figure 12). The charge and discharge curves of the electrochemical and chemical PPy/CNT composites were observed to be perfectly linear with a low ohmic resistance, which indicates prominent capacitive behavior in the cell (Figure 12(a)). The charge as well as discharge time for the cell was maintained constant throughout the cycling, which demonstrates that the electrochemical and chemical PPy/CNT composite electrodes have high electrochemical stability (Figure 12(b)).

In the charge and discharge curves of the electrochemical composite and of the constituent materials, a decrease in the ohmic resistance could be seen, owing to the large aspect ratio and surface area of the CNTs, which may serve as "conducting bridges," connecting conducting PPy domains and increasing the electronic conductivity of these materials (Figure 13).

The specific discharge and charge capacities of the composites and constituent materials values were obtained by (1), in which $C$ is specific capacitance, $j$ is the current density, $\Delta t$ is the time range, $\Delta E$ is the potential range, and $m$ is the mass of the electroactive material:

$$
C=\frac{j \cdot \Delta t}{\Delta E \cdot m}
$$

The chemical PPy/CNT composite exhibited a specific discharge capacitance of $270 \mathrm{Fg}^{-1}$ and power density of $6 \mathrm{~kW} \mathrm{~kg}^{-1}$, with a coulombic efficiency of $93 \%$ after 1000 cycles. The electrochemical PPy/CNT composite device obtained an anodic charge of $Q_{+}=11.38 \mathrm{mC}$ and $\mathrm{a}$ specific discharge capacity of $528 \mathrm{~F} \mathrm{~g}^{-1}$ and power density of $29 \mathrm{~kW} \mathrm{~kg}^{-1}$, with a coulombic efficiency of $99.8 \%$ after 1000 charge and discharge cycles (Table 2 ). The power density values of the chemical and electrochemical composites and their constituent materials were obtained by (2), in which $P$ is power density, $i$ is the current density applied to the charge and discharge tests and an area of $1 \mathrm{~cm}^{2}, \Delta E$ is the potential

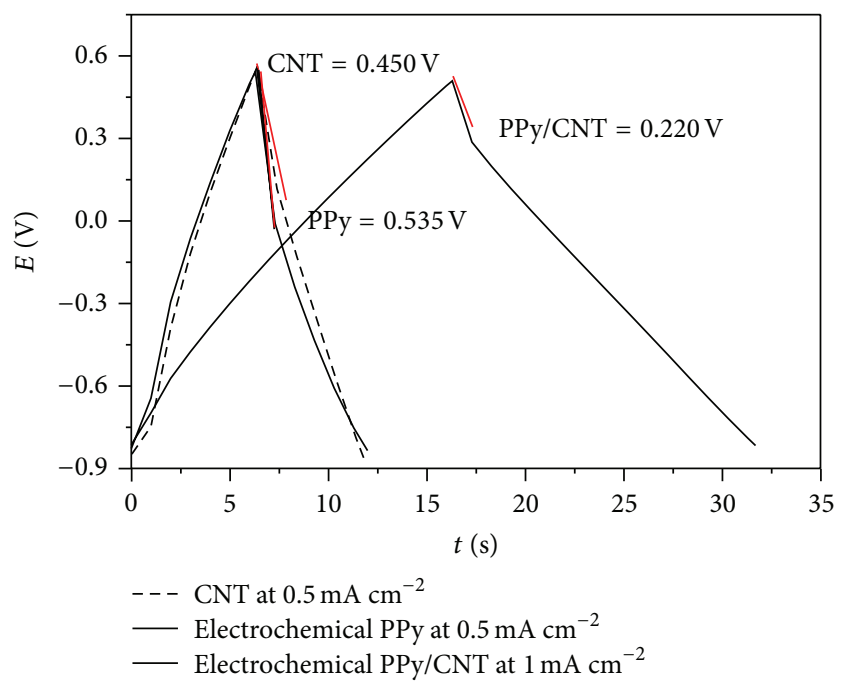

FIGURE 13: Charge and discharge curves of electrochemical and chemical PPy/CNT composites in EC/DMC (50\% v/v) containing $1 \mathrm{~mol} \mathrm{~L}^{-1} \mathrm{LiClO}_{4}$.

range, and $m$ is the mass of the electroactive material. These values are shown in Table 2:

$$
P=\frac{i \cdot \Delta E}{m} .
$$

This specific discharge capacity value of the electrochemical composite was higher than the values obtained for the constituent materials, $105 \mathrm{Fg}^{-1}$ for CNTs and $200 \mathrm{~F} \mathrm{~g}^{-1}$ for PPy after 50 charge and discharge cycles, indicating good electroactivity of this composite during the charge and discharge process (Figure 14). 
TABLE 2: Power density values of the electrochemical and chemical PPy/CNT composites and their constituent materials.

\begin{tabular}{lcccc}
\hline Materials & Specific discharge capacitance/F g & Cycle number & Power density $/ \mathrm{kW} \mathrm{kg}^{-1}$ & Coulombic efficiency/\% \\
\hline Electrochemical PPy/CNT & 528 & 1000 & 29 & 99.80 \\
Chemical PPy/CNT & 270 & 1000 & 6 & 93.00 \\
PPy & 200 & 50 & 12 & 92.50 \\
CNT & 105 & 50 & 7 & 98.10 \\
\hline
\end{tabular}

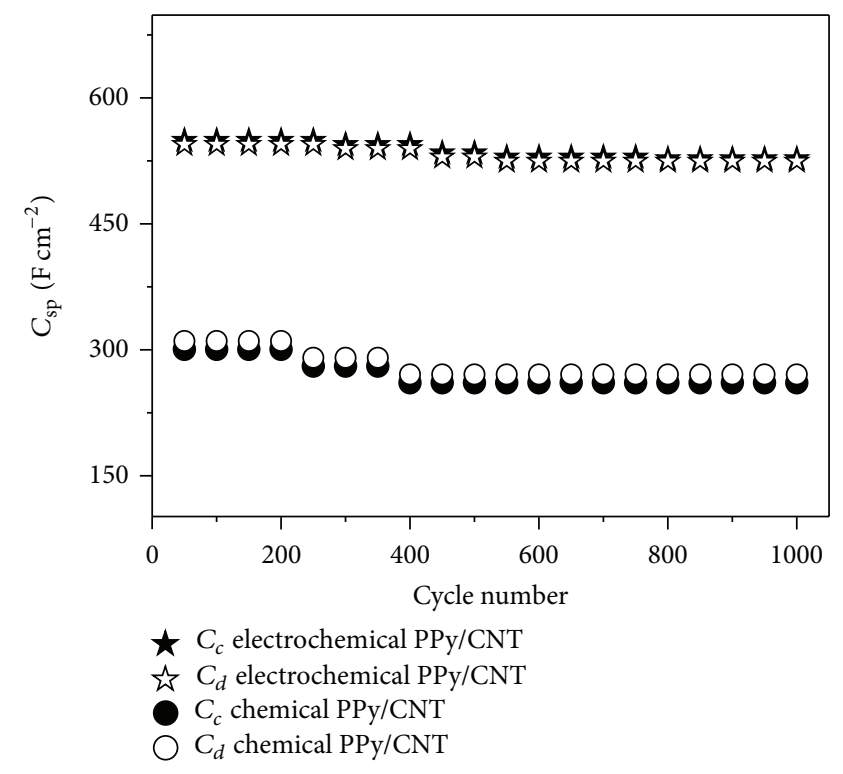

(a)

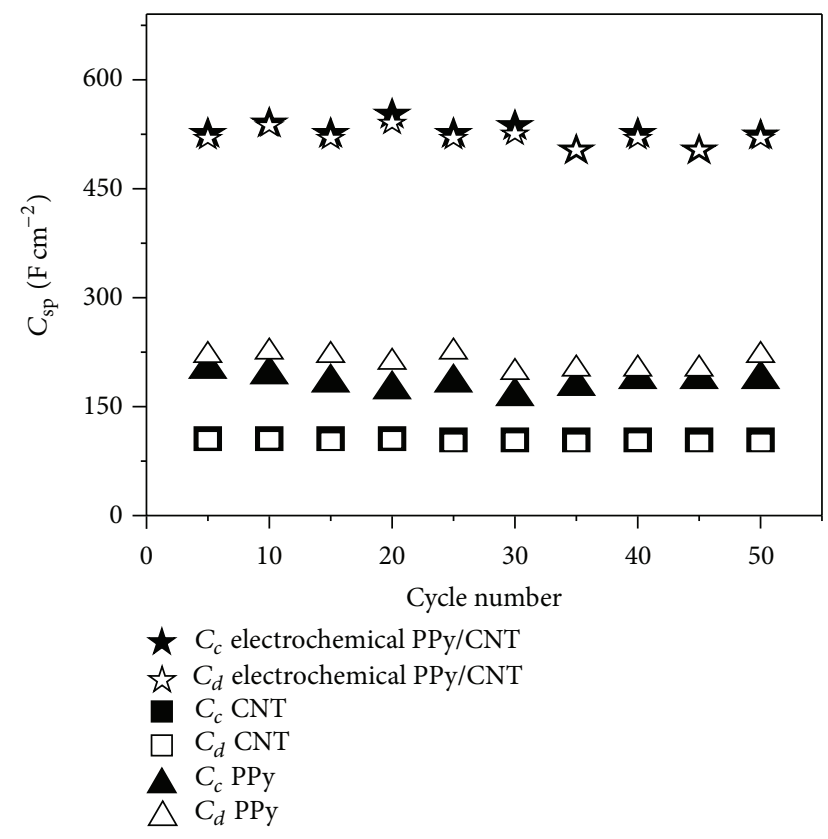

(b)

FIgURE 14: Charge and discharge plots of the specific capacitance values as a function of the cycle number for (a) electrochemical and chemical PPy/CNT composites after 1000 cycles and (b) the electrochemical PPy/CNT composite and its constituent materials after 50 cycles. The current densities of the composites and their constituent material were $1.0 \mathrm{~mA} \mathrm{~cm}^{-2}$ for the electrochemically synthesized PPy/CNT composite, $0.1 \mathrm{~mA} \mathrm{~cm}^{-2}$ for the chemically synthesized PPy/CNT composite, $0.5 \mathrm{~mA} \mathrm{~cm}^{-2}$ for PPy, and $0.1 \mathrm{~mA} \mathrm{~cm}^{-2}$ for the CNTs, in EC/DMC $(50 \% \mathrm{v} / \mathrm{v})$ containing $1 \mathrm{~mol} \mathrm{~L}^{-1} \mathrm{LiClO}_{4}$.

Researchers working with conducting polymer electrodes in supercapacitors have obtained a specific discharge capacity of $176 \mathrm{Fg}^{-1}$ for the electrochemically synthesized PPy/CNT composite in aqueous solution [32,33], which is lower than that obtained for the electrochemically synthesized composite in this work.

\section{Conclusions}

From the FT-IR results of the physical and chemical composites, similar bands to PPy were observed, indicating that the conducting polymer was synthesized on the CNTs. In addition, a band at $1130 \mathrm{~cm}^{-1}$ was observed for the PPy/CNT composite, indicating a high degree of oxidation in PPy and a possible interaction of the surface of the CNTs with the conjugated structure of the conducting polymer. But, comparing the chemically synthesized composite with the physical mixture showed displacement, and the intensification of the band at $1197 \mathrm{~cm}^{-1}$ indicated a higher degree of oxidation in PPy.
The XRD pattern of the composite exhibited two diffraction peaks, and the relative intensities of these reflections were sensitive to the ring-tilt angle and could be attributed to the $\mathrm{Cl}-\mathrm{N}$ distance, which is related to the doping level of the PPy.

The SEM images show a spherical profile of the PPy and a diameter increase of the CNT, indicating the possible growth of the polymer into of the CNTs, showing that the composite was successfully synthesized.

The cyclic voltammograms of the electrodes of the $\mathrm{PPy} / \mathrm{CNT}$ composite showed a predominantly capacitive profile, with current density values higher than those obtained for their constituent materials. The electrochemical stability tests of the device comprising the electrochemical PPy/CNT composite (in both electrodes) exhibited a predominantly capacitive profile, according to $\mathrm{CV}$, with current density values higher than those obtained for the device made from the chemical PPy/CNT composite. In the charge and discharge tests, the current density for the electrochemical composite was higher than that obtained for the chemical composite. Thus, the electrochemical composite presented 
the highest specific discharge capacitance $\left(528 \mathrm{Fg}^{-1}\right.$ after 1000 cycles), power density $\left(29 \mathrm{~kW} \mathrm{~kg}^{-1}\right)$, and $99.8 \%$ coulombic efficiency. The electrochemical PPy/CNT composite showed the best electrochemical properties compared to the chemically synthesized composite, owing to the synergistic effect between constituent materials. The electrochemically synthesized composite showed the lowest impedance values and, consequently, charge-transfer resistance compared to the chemically synthesized and their constituent materials, indicating that electron transfer in the electrochemically synthesized composite was favored by an association between the constituent materials. Thus, from the characterization results using several technics, it is possible to state that the electrochemically synthesized composite is a promising material for use as electrodes in Type I supercapacitors.

\section{Conflict of Interests}

The authors declare that there is no conflict of interests regarding the publication of this paper.

\section{Acknowledgment}

This work was supported by FAPEMIG (Grants APQ2279 and EX027-2013).

\section{References}

[1] M. G. Kanatzidis, "Conductive polymers," Chemical and Engineering News, vol. 68, no. 49, pp. 36-54, 1990.

[2] D. J. Maia, M.-A. De Paoli, O. L. Alves, A. J. G. Zarbin, and S. Das Neves, "Síntese de polímeros condutores em matrizes sólidas hospedeiras," Química Nova, vol. 23, no. 2, pp. 204-215, 2000.

[3] E. Desimoni, B. Brunetti, P. Ugo, and R. Cazzaniga, "A polypyrrole/ $\mathrm{Fe}(\mathrm{CN})_{6}^{3-/ 4-}$-coated piezoelectric sensor for $\mathrm{Cr}(\mathrm{VI})$," Synthetic Metals, vol. 130, no. 2, pp. 135-137, 2002.

[4] Y. Kudoh, S. Tsuchiya, T. Kojima, M. Fukuyama, and S. Yoshimura, "An aluminum solid electrolytic capacitor with an electroconducting-polymer electrolyte," Synthetic Metals, vol. 41, no. 3, pp. 1133-1136, 1991.

[5] C. G. J. Koopal, M. C. Feiters, R. J. M. Nolte, B. de Ruiter, and R. B. M. Schasfoort, "Third-generation amperometric biosensor for glucose. Polypyrrole deposited within a matrix of uniform latex particles as mediator," Bioelectrochemistry and Bioenergetics, vol. 29, no. 2, pp. 159-175, 1992.

[6] B. Deore, Z. D. Chen, and T. Nagaoka, "Potential-induced enantioselective uptake of amino acid into molecularly imprinted overoxidized polypyrrole," Analytical Chemistry, vol. 72, no. 17, pp. 3989-3994, 2000.

[7] E. Smela, O. Inganäs, and I. Lundström, "Controlled folding of micrometer-sized structures," Science, vol. 268, no. 5218, pp. 1735-1738, 1995.

[8] S. Iijima, "Helical microtubules of graphitic carbon," Nature, vol. 354, no. 6348, pp. 56-58, 1991.

[9] M. H. Herbst, M. I. F. Macêdo, and A. M. Rocco, "Technology of carbon nanotubes: trends and perspectives of a multidisciplinary area," Química Nova, vol. 27, no. 6, pp. 986-992, 2004.

[10] J. G. V. Romero, C. A. Luengo, J. G. Huber, and J. M. Rosolen, "Synthesis of single-wall nanotubes by pyrolysis of graphite in
Helium atmosphere," Química Nova, vol. 25, no. 1, pp. 59-61, 2002.

[11] E. T. Thostenson, Z. Ren, and T.-W. Chou, "Advances in the science and technology of carbon nanotubes and their composites: a review," Composites Science and Technology, vol. 61, no. 13, pp. 1899-1912, 2001.

[12] J. Wang, Y. Xu, X. Chen, and X. Sun, "Capacitance properties of single wall carbon nanotube/polypyrrole composite films," Composites Science and Technology, vol. 67, no. 14, pp. 29812985, 2007.

[13] J. Zhao, H. Park, J. Han, and J. P. Lu, "Electronic properties of carbon nanotubes with covalent sidewall functionalization," Journal of Physical Chemistry B, vol. 108, no. 14, pp. 4227-4230, 2004.

[14] T. Ramanathan, F. T. Fisher, R. S. Ruoff, and L. C. Brinson, "Amino-fimctionalized carbon nanotubes for binding to polymers and biological systems," Chemistry of Materials, vol. 17, no. 6, pp. 1290-1295, 2005.

[15] P. Li, Y. Yang, E. Shi et al., "Core-double-shell, carbon nanotube@polypyrrole@ $\mathrm{MnO}_{2}$ sponge as freestanding,compressible supercapacitor electrode," ACS Applied Materials and Interfaces, vol. 6, no. 7, pp. 5228-5234, 2014.

[16] S. Dhibar and C. K. Das, "Silver nanoparticles decorated polyaniline/multiwalled carbon nanotubes nanocomposite for high-performance supercapacitor electrode," Industrial and Engineering Chemistry Research, vol. 53, no. 9, pp. 3495-3508, 2014.

[17] X.-T. Huo, P. Zhu, G.-Y. Han, and J.-J. Xiong, "Preparation and performance of carbon/polypyrrole membranes as an electrode in supercapacitors," New Carbon Materials, vol. 28, no. 6, pp. 414-420, 2013.

[18] Y. Hu, Y. Zhao, Y. Li, H. Li, H. Shao, and L. Qu, "Defective superlong carbon nanotubes and polypyrrole composite for highperformance supercapacitor electrodes," Electrochimica Acta, vol. 66, pp. 279-286, 2012.

[19] S. C. Canobre, D. A. L. Almeida, C. Polo Fonseca, and S. Neves, "Synthesis and characterization of hybrid composites based on carbon nanotubes," Electrochimica Acta, vol. 54, no. 26, pp. 6383-6388, 2009.

[20] N. G. Sahoo, Y. C. Jung, H. H. So, and J. W. Cho, "Polypyrrole coated carbon nanotubes: synthesis, characterization, and enhanced electrical properties," Synthetic Metals, vol. 157, no. 89, pp. 374-379, 2007.

[21] R. A. Davoglio, S. R. Biaggio, R. C. Rocha-Filho, and N. Bocchi, "Bilayered nanofilm of polypyrrole and poly(DMcT) for highperformance battery cathodes," Journal of Power Sources, vol. 195, no. 9, pp. 2924-2927, 2010.

[22] D. R. S. Jeykumari, S. Ramaprabhu, and S. S. Narayanan, "A thionine functionalized multiwalled carbon nanotube modified electrode for the determination of hydrogen peroxide," Carbon, vol. 45, no. 6, pp. 1340-1353, 2007.

[23] R. Rajagopalan and J. O. Iroh, "A one-step electrochemical synthesis of polyaniline-polypyrrole composite coatings on carbon fibers," Electrochimica Acta, vol. 47, no. 12, pp. 1847-1855, 2002.

[24] K. S. Ryu, B. W. Moon, J. Joo, and S. H. Chang, "Characterization of highly conducting lithium salt doped polyaniline films prepared from polymer solution," Polymer, vol. 42, no. 23, pp. 9355-9360, 2001.

[25] J. Fan, M. Wan, D. Zhu, B. Chang, Z. Pan, and S. Xie, "Synthesis, characterizations, and physical properties of carbon nanotubes 
coated by conducting polypyrrole," Journal of Applied Polymer Science, vol. 74, no. 11, pp. 2605-2610, 1999.

[26] J. P. Pouget, M. E. Jozefowicz, A. J. Epstein, X. Tang, and A. G. MacDiarmid, "X-ray structure of polyaniline," Macromolecules, vol. 24, no. 3, pp. 779-789, 1991.

[27] W.-C. Chen and T.-C. Wen, "Electrochemical and capacitive properties of polyaniline-implanted porous carbon electrode for supercapacitors," Journal of Power Sources, vol. 117, no. 1-2, pp. 273-282, 2003.

[28] Z. Huseyin, Z. Wensheng, J. Jianyong et al., "Carbon nanotubes doped polyaniline," Advanced Materials, vol. 14, no. 20, pp. 1480-1483, 2000.

[29] C. G. J. Koopal, M. C. Feiters, R. J. M. Nolte, B. de Ruiter, and R. B. M. Schasfoort, "Third-generation amperometric biosensor for glucose. Polypyrrole deposited within a matrix of uniform latex particles as mediator," Bioelectrochemistry and Bioenergetics, vol. 29, no. 2, pp. 159-175, 1992.

[30] B. Deore, Z. Chen, and T. Nagaoka, "Potential-induced enantioselective uptake of amino acid into molecularly imprinted overoxidized polypyrrole," Analytical Chemistry, vol. 72, no. 17, pp. 3989-3994, 2000.

[31] W. Sun and X. Chen, "Preparation and characterization of polypyrrole films for three-dimensional micro supercapacitor," Journal of Power Sources, vol. 193, no. 2, pp. 924-929, 2009.

[32] M. Nagaraja, H. M. Mahesh, J. Manjanna, K. Rajanna, M. Z. Kurian, and S. V. Lokesh, "Effect of multiwall carbon nanotubes on electrical and structural properties of polyaniline," Journal of Electronic Materials, vol. 41, no. 7, pp. 1882-1885, 2012.

[33] R. Rajagopalan and J. O. Iroh, "Characterization of polyanilinepolypyrrole composite coatings on low carbon steel: a XPS and infrared spectroscopy study," Applied Surface Science, vol. 218, no. 1-4, pp. 58-69, 2003. 

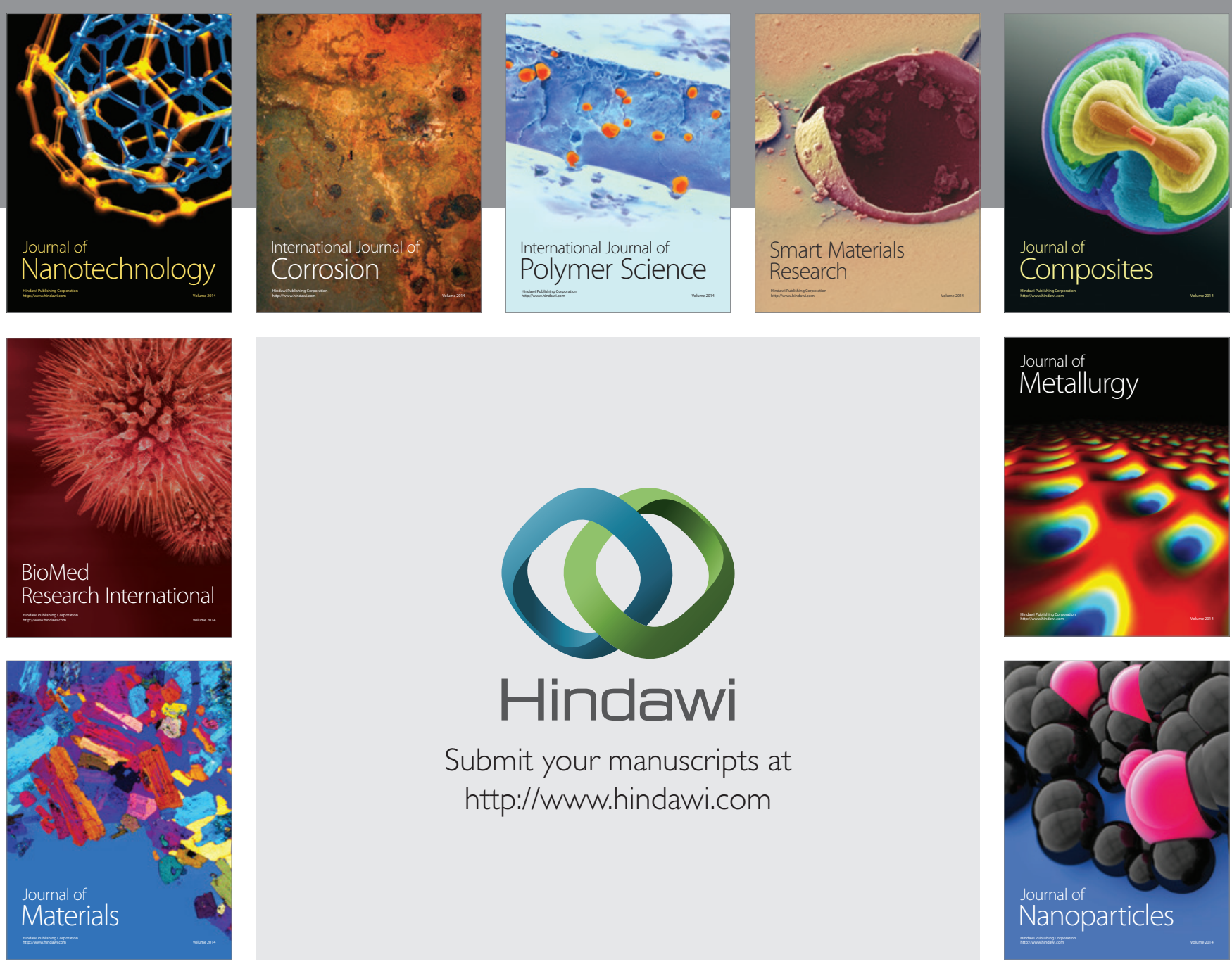

Submit your manuscripts at http://www.hindawi.com
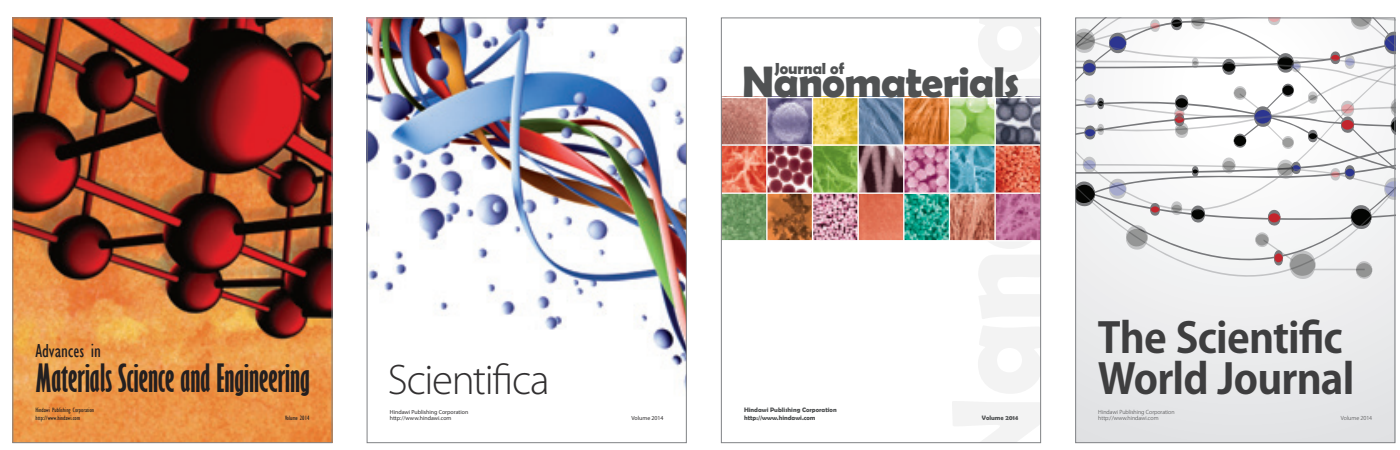

\section{The Scientific World Journal}
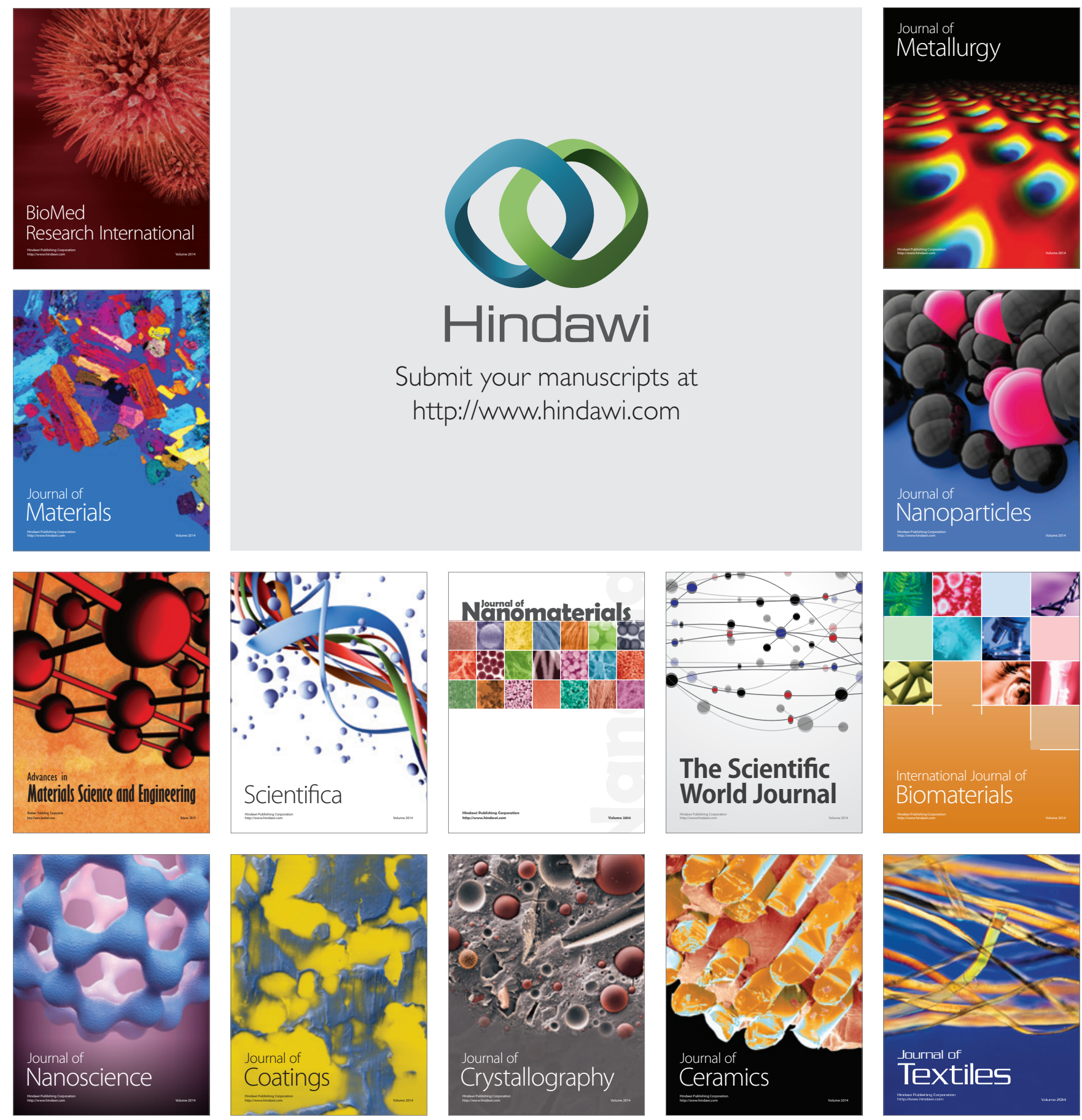